\title{
Inclusão no ensino superior: a percepção de docentes de uma instituição pública do interior do estado de São Paulo
}

\author{
Rosimar Bortolini Poker \\ Universidade Estadual Paulista - Faculdade de Filosofia e Ciências - Marília - São Paulo - Brasil \\ Fernanda Oscar Dourado Valentim \\ Universidade Estadual Paulista - Faculdade de Filosofia e Ciências - Marília - São Paulo - Brasil \\ Isadora Almeida Garla \\ Universidade Estadual Paulista - Faculdade de Filosofia e Ciências - Marília - São Paulo - Brasil
}

\section{Resumo}

Na última década, o movimento da educação inclusiva alcançou o ensino superior e exigiu mudanças em suas condições de acesso e de permanência. Nesse contexto, a pesquisa buscou investigar e analisar a percepção de docentes de uma universidade sobre o processo de inclusão de alunos com deficiência. Foram considerados fatores que poderiam interferir na sua percepção, tais como contato com aluno com deficiência, atitudes tomadas na sala de aula, conhecimento sobre inclusão e, também, o suporte e apoios oferecidos pela instituição. Teve como base o estudo de caso dos docentes da Faculdade de Filosofia e Ciências (FFC), Unesp, Campus de Marília/SP. Os dados coletados a partir de um questionário indicaram que os docentes têm uma percepção favorável quanto ao processo de inclusão; entretanto, reconhecem que suas atitudes são falhas e sua formação na área é incipiente, o que os leva a sentir insegurança e despreparo. A instituição também foi foco de críticas pelos professores.

Palavras-chave: Educação Inclusiva; instituições de ensino superior; medidas de atitude.

\section{Inclusion in higher education: the perception of teachers of a public institution in the interior of the state of São Paulo}

\begin{abstract}
In the last decade, the inclusive education movement has reached higher education and demanded changes in its conditions of access and permanence. In this context, the research sought to investigate and analyze the perception of university teachers about the inclusion process of students with disabilities. It was considered factors that could interfere with their perception, such as contact with students with disabilities, attitudes have taken in the classroom, knowledge about inclusion and also the support and support offered by the institution. It was based on the case study of the professors of the Faculty of Philosophy and Sciences (FFC), Unesp, Marilia Campus / SP. The data collected from a questionnaire indicated that teachers have a favorable perception regarding the inclusion process; however, they recognize that their attitudes are flawed and their training in the area is incipient, which leads them to feel insecure and unprepared. The institution was also the focus of criticism by teachers. Keywords: Inclusive Education; higher education institutions; attitude measures.
\end{abstract}

\section{Inclusión en la enseñanza universitaria: percepción de docentes de una institución pública del interior del estado de São Paulo}

\section{Resumen}

En la última década, el movimiento de la educación inclusiva alcanzó la enseñanza universitaria y exigió cambios en sus condiciones de acceso y de permanencia. En ese contexto, la investigación ha buscado indagar y analizar la percepción de docentes de una universidad sobre el proceso de inclusión de alumnos con deficiencia. Se consideró factores que podrían interferir en su percepción, tales como contacto con alumno con deficiencia, actitudes adoptadas en la sala de clase, conocimiento sobre inclusión y, también, el soporte y apoyos ofrecidos por la institución. Se tuvo como base el estudio de caso de los docentes de la Facultad de Filosofía y Ciencias (FFC), Unesp, Campus de Marília/SP. Los datos recolectados a partir de un cuestionario indicaron que los docentes tienen una percepción favorable cuanto al proceso de inclusión; sin embargo, reconocen que sus actitudes son fallas y su formación en el área es incipiente, lo que los lleva a sentir inseguridad y falta de preparación. La institución también fue enfoque de críticas por los profesores.

Palabras clave: Educación Inclusiva; instituciones de enseñanza universitaria; medidas de actitud. 


\section{Introdução}

No Brasil, a década de 1990 pode ser compreendida como um marco de mudança paradigmática na política educacional brasileira. Decretos, resoluções, recomendações e diretrizes foram promulgados de forma a orientar os sistemas educacionais em uma perspectiva inclusiva, tendo como princípios a igualdade, a equidade e o atendimento à diversidade em ambientes regulares de ensino. Os sistemas de ensino passaram a se organizar para atender as necessidades educacionais de todos os alunos, inclusive das pessoas com deficiência, respeitando suas especificidades por meio de adequações no espaço físico e na implementação de serviços de apoio, bem como no fazer pedagógico.

Sob a influência de documentos provenientes de conferências internacionais tais como a Declaração de Jomtien (1990) e a Declaração de Salamanca (1994), a nova Lei de Diretrizes e Bases da Educação Nacional (LDB) (Lei n 9.394, 1996), aprovada em 1996, explicita a opção por uma política pública inclusiva que prevê o acesso e a permanência dos alunos com necessidades educacionais específicas na escola com o apoio de estratégias, recursos e metodologias diferenciadas, a previsão do atendimento educacional especializado e, ainda, a preocupação com a formação dos professores da educação especial e do ensino regular para atuar com a diversidade do alunado. Verifica-se assim um crescente número de ações no âmbito governamental que atingem a escola e a sociedade em geral, destinadas à garantia da igualdade de direitos e à negação de quaisquer formas de discriminação.

O movimento de inclusão que se expandiu na educação básica nos últimos anos alcança, também, o ensino superior, subsidiado por normativas legais que tratam da garantia de direitos, tais como o Aviso Circular $n^{\circ}$ 277/1996 (Brasil, 1996), o Decreto $n^{\circ} 3.298 / 1999$ (1999), a Portaria $n^{0} 3.284 / 2003$ (2003) e recentemente a Lei $n^{\circ} 13.146 / 2015$ (2015), Lei Brasileira de Inclusão da Pessoa com Deficiência. É expressiva a ampliação do número de pessoas com deficiência que reivindicam o direito de ingressar e de permanecer nas universidades, o que tem provocado mudanças conceituais e atitudinais dos professores, bem como nas condições de acessibilidade ao ensino superior.

Segundo Moreira, Bolsanello e Seger (2011), da mesma forma que a educação básica tem buscado atender os princípios da inclusão assegurando apoios e recursos físicos, humanos e materiais aos alunos com necessidades educacionais específicas, o ensino superior passa a incorporar essa exigência.

As pessoas com deficiência, que tradicionalmente eram expectadores, agora entram em cena, assumindo vez e voz. Estão chegando ao ensino superior, ainda que de forma tímida, mas demandando novas posturas de gestores, de professores, de técnicos- administrativos, de alunos e da própria pessoa com deficiência. Essa questão se torna relevante, considerando que o número de alunos com deficiência no ensino superior tem aumentado, bem como tem se ampliado a preocupação em garantir os seus direitos, que não são apenas de acesso, mas também de permanência e alcance do sucesso acadêmico nesse nível de ensino (Guerreiro, Almeida, \& Silva Filho, 2014, p. 32).

O desafio que se impõe hoje à universidade brasileira é grande, pois precisa articular a democratização do acesso a um nível de ensino que exige processo seletivo e, ao mesmo tempo, a garantia da qualidade do ensino superior a todos os alunos, inclusive aos que apresentam condições sensoriais, físicas, intelectuais, comportamentais e motoras diferenciadas e que, de alguma forma, afetam o seu processo de ensino e de aprendizagem.

Mas como equilibrar a tensão existente entre atender os princípios da inclusão, garantindo acesso e permanência dos alunos com deficiência no ensino superior, e a condição desse alunado para acompanhar tal nível de ensino? Diferentemente da educação básica, que tem como objetivo assegurar a todos a formação comum indispensável para o exercício da cidadania, conforme indica o art. 43 da LDB (Lei no 9.394, 1996), uma das finalidades da educação superior é formar diplomados nas diferentes áreas de conhecimento, aptos à inserção em setores profissionais. Tal especificidade precisa ser considerada na implementação da inclusão, pois demanda transformações complexas na estrutura e no funcionamento da universidade e consequentemente na forma de pensar e de agir dos seus professores. De um modelo de ensino superior que, historicamente, formava futuros profissionais com base na seleção e na competitividade, agora, com a inclusão, propõe-se o acolhimento de todos os alunos, atendendo suas especificidades para aprender, garantindo-Ihes a acessibilidade necessária. Será que essa transformação é possível?

O Instituto Nacional de Estudos e Pesquisas (Inep), por meio dos dados divulgados no resumo técnico do Censo da Educação Superior (Inep, 2015), indica que 7.305.977 estudantes brasileiros efetuaram matrículas em Instituições de Ensino Superior, em 2013. Dessa amostra total, 29.034 declararam apresentar alguma necessidade especial constitutiva do público-alvo da educação especial, ou seja, alunos com deficiência, transtornos globais de desenvolvimento e altas habilidades/superdotação.

Aliado à questão legal, esse aumento de matrícula do alunado público-alvo da educação especial nos cursos de graduação nas Instituições de Ensino Superior (IES) é explicado pela implementação de programas governamentais de educação inclusiva voltados especificamente ao ensino superior. Entre eles, podem ser citados o Plano de Reestruturação e Expansão das Universidades Federais - REUNI, o Programa Universidade para Todos - PROUNI e especificamente o Programa de Inclusão no Ensino Superior - INCLUIR, que tem por finalidade assegurar o direito da pessoa com deficiência à educação superior, fomentando a criação e a consolidação de núcleos de acessibilidade nos Institutos Federais de Ensino Superior. Cumprindo o disposto nos decretos $n^{\circ} 5.296 / 2004$ (Decreto $n^{\circ} 5.296 / 2004,2004$ ) e $n^{\circ} 5.626 / 2005$ (Decreto $n^{\circ}$ 5.626/2005, 2005) o programa INCLUIR 04/2008 pretende 
viabilizar ações institucionais nas universidades para integrar as pessoas com deficiência à vida acadêmica e eliminar as barreiras pedagógicas, comportamentais, arquitetônicas e de comunicação que possam existir. Acrescenta-se ainda a promulgação da Política Nacional de Educação Especial na perspectiva da Educação Inclusiva, aprovada em 2008 (Brasil, 2008), que propõe a transversalidade da educação especial também no ensino superior.

Entretanto, nem toda universidade tem cumprido as orientações e normativas legais existentes. Trata-se de um processo que demanda mudanças complexas e por isso mesmo é lento, gradual e contínuo. Conforme acrescentam Moreira, Bolsanello e Seger (2011),

... uma universidade inclusiva só é possível no caminhar em busca da mudança que vai eliminando barreiras de toda ordem, desconstruindo conceitos, preconceitos e concepções segregadoras e excludentes. É um processo que nunca está finalizado, mas que, coletivamente, deve ser constantemente enfrentado. (p. 141).

As condições de acesso e permanência do aluno com deficiência no ensino superior não implica apenas a construção de espaços fisicamente acessíveis, mas também recursos pedagógicos (livros, equipamentos, instrumentos etc.), informações para a comunidade técnico-administrativa, instruções e/ ou capacitação aos professores e apoio institucional. Portanto, há que se proporcionar uma mudança no modus operandi de uma instituição no seu fazer tradicional tanto no ensino, na pesquisa e na extensão quanto na infraestrutura oferecida a toda a comunidade docente, discente e administrativa.

Esse é um momento histórico-social desafiador, pois tornar o ensino superior igualmente acessível a todos os que desejam cursá-lo é uma tarefa complexa. Exige o delineamento de atitudes pautadas na eliminação das barreiras que dificultam ou impedem a plena participação dessa população nas diferentes esferas sociais. Dito de outro modo, problematizar as condições de acessibilidade na universidade, em especial as percepções dos docentes, implica, por conseguinte, conceber o ensino superior como um espaço democrático, formador de opiniões e de produção de conhecimento, que combate a discriminação e o preconceito.

Nesse contexto, a presente pesquisa analisou as percepções de professores universitários de uma faculdade pública, vinculada a uma universidade estadual paulista do interior do Estado de São Paulo, sobre a inclusão da pessoa com deficiência no ensino superior. Buscou-se identificar aspectos da formação dos docentes que poderiam interferir em suas percepções e em suas atitudes em sala de aula junto aos alunos com deficiência, bem como verificar como avaliam a própria instituição.

\section{Metodologia}

O estudo é parte integrante da pesquisa em rede "Acessibilidade no Ensino Superior", uma parceria entre a
Universidade Estadual Paulista (UNESP) e o Programa Observatório em Educação (OBEDUC) - CAPES. Usando como método o Estudo de Caso, a pesquisa, de natureza descritiva, buscou compreender um fenômeno social complexo, apresentando as características de um grupo com base na análise quantitativa e qualitativa dos dados. Segundo André (2005), o estudo de caso promove a compreensão do leitor sobre o fenômeno estudado, podendo, por meio da indução, vir a descobrir novos significados e afirmar ou não o que já foi conhecido.

O lócus da pesquisa foi a Faculdade de Filosofia e Ciências - FFC - Unesp/Marília, uma dentre as 34 unidades da UNESP espalhadas pelo Estado de São Paulo. Inicialmente foi feito um levantamento dos nomes e emails dos docentes que em 2015 ministraram aulas nos cursos da faculdade, que são Pedagogia, Biblioteconomia, Arquivologia, Filosofia, Ciências Sociais, Relações Internacionais, Fisioterapia, Fonoaudiologia e Terapia Ocupacional. Em seguida, foram enviados questionários para todos os 162 docentes da unidade, com retorno de 52 , o que corresponde a uma amostra de aproximadamente $32 \%$ dos sujeitos. O instrumento de coleta continha duas perguntas abertas e 28 perguntas fechadas; destas, oito de múltipla escolha, com possibilidade de assinalar mais de uma alternativa, e 20 dicotômicas. As perguntas versaram sobre dados gerais dos participantes, sua atuação profissional, formação, qualificação, experiência docente com alunos com deficiência, conhecimento sobre educação especial/inclusiva, atitudes tomadas, barreiras e os apoios institucionais existentes. Para a construção e envio do questionário on line aos participantes, foi utilizada a Plataforma do Gmail Google Drive.

\section{Resultados}

\section{Caracterização}

Dos 52 professores participantes distribuídos pelos diferentes cursos da FFC - Unesp/Marília, 31 são do sexo feminino e 21 do masculino. Sobre a faixa etária, seis tinham entre 31 e 40 anos; a maioria, 25 docentes, tinha entre 41 e 50 anos; e 21 docentes tinham 51 anos ou mais. Em relação ao tempo de trabalho em Instituições de Ensino Superior, $71 \%$ dos docentes atuam na profissão há mais de quinze anos; $19 \%$ entre seis e quinze anos e só $10 \%$ atuam entre um e cinco anos. Considerando a idade e tempo de trabalho verificado, seria esperado que a maioria dos docentes tivesse contato com o tema inclusão durante a sua formação. Isso porque tal paradigma está presente nas políticas educacionais desde 1990.

\section{Formação e qualificação docente}

Dos 52 docentes, dois são doutorandos e 50 têm título de doutor. 16 fizeram pós-doutorado e seis são livres-docentes. 
A maioria realizou mestrado e doutorado na área de concentração em Educação, e em menor número na área da saúde. Um professor finalizou o doutorado entre 1980 e 1990; 13 finalizaram de 1991 a 2000 e 36 de 2001 até 2010. Sem dúvida alguma, os docentes participantes são academicamente muito qualificados.

Porém, quando tratada a questão sobre a formação em educação inclusiva, menos da metade deles, ou seja, $45 \%$, teve acesso a conteúdos relacionados ao tema durante a sua formação acadêmica. Apenas 33\% participaram de alguma formação complementar nessa área (palestras, cursos, oficinas e/ou eventos). Quando discriminaram os conhecimentos abrangidos nessas formações, indicaram, em sua maioria, que focaram aspectos legais, filosóficos e conceituais a respeito da educação inclusiva. Tal dado evidencia que a formação inicial e continuada não está atingindo a maioria dos docentes que atuam no ensino superior, e quando tal formação ocorre, não trata necessariamente de temas relacionados à prática pedagógica em sala de aula e inclusão, ou seja, uso de materiais, recursos ou conhecimento sobre as necessidades educacionais dos alunos com deficiência.

Outro aspecto intrigante revelado é que mesmo tendo a formação acadêmica finalizada nas duas últimas décadas, período em que a política inclusiva foi implementada, a maioria dos docentes, $55 \%$, não teve contato com o tema. Considerando que os professores participantes tiveram sua formação vinculada à área das ciências humanas e/ou da saúde, cabem aqui algumas reflexões: os cursos de graduação e os programas de pós-graduação estão preocupados com a questão da educação inclusiva? Reconhecem a inclusão da pessoa com deficiência como um tema importante para a formação docente? Parece que não.

Estudos de Baptaglin e Souza (2012), Ferrari e Sekkel (2007) e Regiani e Mól (2013) verificaram esse mesmo fenômeno. Apontam falta de formação no âmbito da educação inclusiva, ausência de reforma dos programas de formação de professores e a ausência da disciplina LIBRAS - Língua Brasileira de sinais em cursos de licenciatura. A formação docente insuficiente acaba sendo um dos maiores obstáculos para a educação inclusiva e se agrava por sabermos que a maioria dos docentes das ciências são bacharéis e não licenciados (Pacheco \& Costa, 2006). Assim, além de políticas públicas para o acesso e permanência, é preciso favorecer a formação e capacitação dos docentes através de cursos de qualificação e formação continuada para que realmente haja uma inclusão que preze pelo respeito e reconhecimento das diversidades, de maneira que todos possam se beneficiar (Castanho \& Freitas, 2006).

\section{Experiência docente com alunos com deficiência}

Dentre os $79 \%$ dos participantes que afirmaram já ter tido experiência docente com alunos com deficiência na FFC - Unesp/Marília, verificou-se que $38 \%$ tiveram alunos com deficiência física, $28 \%$ com deficiência visual, $26 \%$ com deficiência auditiva/surdez e $8 \%$ apontaram que tiveram alu- nos com autismo ou outra deficiência não identificada. Tais dados, quando relacionados ao sentimento de segurança do docente para atuar com alunos com deficiência, revelam aspectos interessantes, pois os $43 \%$ de docentes que manifestaram que se sentem seguros e preparados tiveram experiências com alunos que apresentavam deficiências que exigiam baixo nível de adequações, tais como alunos cadeirantes ou com deficiência auditiva moderada. Já os $57 \%$ que manifestaram insegurança e falta de preparo para atuar junto a esse alunado tiveram experiências com alunos que demandavam adequações muito significativas da aula, tais como alunos com cegueira, autismo e/ou surdez.

\section{Apoio da instituição de ensino superior}

Sobre a oferta de apoios e recursos para o atendimento dos alunos com deficiência na FFC - Unesp/Marília, apenas $25 \%$ consideraram que a instituição ofereceu todo o apoio necessário, e $75 \%$ manifestaram que não tiveram apoio ou que o apoio existente foi insuficiente. Isso pode ser justificado porque a referida faculdade fornece uma ajuda financeira, denominada bolsa-permanência, para os alunos com deficiência, e de acordo com os participantes, esse apoio isoladamente não garante as condições adequadas de ensino e de aprendizagem para o aluno.

Quando perguntados sobre o conhecimento que tinham quanto aos direitos dos alunos com deficiência no ensino superior, $22 \%$ apontaram que não sabiam que a faculdade é que deveria oferecer todo o apoio e recursos necessários, seja para o aluno ou para o professor. Sobre essa questão, em pesquisa com docentes de ensino superior da Universidade Federal do Piauí, Souza (2008) revelou uma situação semelhante. Em sua maioria, não conheciam a existência de apoios e ações voltadas para suprir as necessidades dos alunos com deficiência na instituição. Mesmo compondo uma minoria de docentes (22\%), tal situação é preocupante, pois inviabiliza a mobilização da comunidade universitária no sentido de pressionar os gestores responsáveis pela implementação de uma política inclusiva na instituição.

Em relação às condições de acessibilidade oferecidas pela faculdade para garantir o acesso e a permanência de alunos com deficiência, apenas $8 \%$ consideraram plenamente adequadas. Nenhum docente citou a questão do vestibular que, no caso dessa universidade, ainda não é acessível. As críticas trazidas por $92 \%$ dos docentes focaram aspectos relacionados à permanência, tais como a preocupação com a estrutura física que não é plenamente acessível, a falta de recursos materiais específicos e a inexistência de apoio especializado como, por exemplo, a contratação de intérpretes para alunos surdos. Alguns docentes indicaram, inclusive, que a falta de conhecimento deles próprios sobre o tipo de deficiência do aluno e sobre recursos e/ou tecnologias constitui a principal barreira a ser enfrentadas.

Vale ressaltar que, conforme apontam Melo e Gonçalves (2013, p.87), a 
inclusão desse alunado nas Instituições de Ensino Superior (IES) deve prever adequações desde o momento do ingresso por meio do processo seletivo vestibular, bem como durante sua permanência, de modo a garantir os apoios necessários para o desenvolvimento e terminalidade com sucesso de sua formação na graduação preparando-o para o mercado de trabalho.

Corrobora essa ideia o estudo de Moreira e cols. (2011) sobre o suporte oferecido pela instituição de ensino superior, feito por meio de relatos de alunos com deficiência. Nele, constatou-se que as adaptações e recursos utilizados na sala de aula, constituem aspectos determinantes que colaboram positivamente com o seu percurso acadêmico.

Baptaglin e Souza (2012), também reiterando os achados da presente pesquisa, salientam pontos negativos muito presentes na inclusão no ensino superior: presença de barreiras estruturais das IES, desqualificação dos recursos humanos, problemas nas condições de trabalho e de saúde dos professores, baixa qualidade das aulas universitárias, limites da política do PROUNI, falta de condições que garantem o acesso (políticas de inclusão, atitudes e aquisição de produtos e tecnologias assistivas), o modo como os docentes representam a deficiência ou as necessidades educacionais especiais e como isso reflete nas práticas de sala de aula.

\section{Conhecimento sobre Educação Especial/Inclusiva}

A maioria dos docentes, 96\%, manifestou opinião plenamente favorável acerca da inclusão de alunos com deficiência no ensino superior. Apenas 4\% disseram que ainda não possuem uma ideia formada sobre o assunto. Quando descreveram o que significava a inclusão, as 41 respostas obtidas referiram-se, de alguma forma, aos princípios que fundamentam a educação inclusiva, tais como direito à educação, oportunidade de integração, condições de acesso e permanência, direito ao pleno desenvolvimento escolar, criação de condições para a independência e garantia de ensino de qualidade para todos. É interessante notar que um estudo de Souza (2008) sobre as concepções de docentes de uma universidade acerca da inclusão educacional de pessoas com deficiência revelou que eles são favoráveis à inclusão de pessoas com deficiência na universidade, porém, a maioria revelou conhecer pouco sobre o assunto, assim como desconhecer a existência de ações e apoios à inclusão naquela universidade, sobretudo no que diz respeito aos apoios necessários ao processo de ensino e de aprendizagem.

No caso do presente estudo, o alto índice de professores a favor da inclusão no ensino superior pode estar relacionado ao ambiente acadêmico proporcionado pela instituição que trabalham. Apesar de só $45 \%$ terem formação na graduação e pós-graduação na área da inclusão, $87 \%$ afirmaram que já tiveram contato com o tema educação inclusiva durante sua trajetória profissional e que conhecem as bases conceituais desse paradigma. Esse dado pode ser explicado pelo seguinte fato: os docentes participantes mi- nistram aulas em cursos das áreas da saúde e das ciências humanas; consequentemente, tiveram mais oportunidades de vivenciar situações que tratam do tema, tais como participação em bancas, eventos e cursos. Vale ressaltar que, na faculdade em que atuam, há um departamento de educação especial e uma linha de pesquisa do programa de pós-graduação também nessa área. Parece que esse contexto explica as razões pelas quais o estudo aqui apresentado difere do que verificou a pesquisa de Souza (2008), em que a maioria dos professores relatou desconhecer ou mesmo possuir informações difusas acerca dos fundamentos da inclusão, notadamente no tocante às bases conceituais.

\section{Barreiras e atitudes do professor}

A questão de múltipla escolha que tratou sobre as barreiras existentes mostrou um dado interessante: $84 \%$ das respostas referiram a formação profissional precária como a principal barreira para a inclusão. Em seguida, com $71 \%$ das respostas, aparecem as barreiras arquitetônicas, e depois, com $49 \%$, as barreiras atitudinais. Verifica-se uma correlação entre os dados, pois a falta de conhecimento na área dificulta ou mesmo impede que a universidade seja acessível tanto no âmbito físico quanto em relação aos conteúdos curriculares. Como não há conhecimento acerca das necessidades especiais do aluno, a comunidade universitária não se mobiliza; não faz as adequações necessárias para se garantir as condições de aprendizagem desse aluno.

Tais dados equiparam-se à pesquisa de Castro e Almeida (2014). Nela, quando os alunos com deficiência foram questionados sobre quais eram as maiores barreiras para sua inclusão, também enfatizaram a falta de acessibilidade física, barreiras comunicacionais, atitudinais e barreiras pedagógicas, estas, caracterizadas como referentes à didática em sala de aula, a utilização de métodos inadequados, a falta de preparo dos professores para identificar as necessidades dos alunos com deficiência e a falta de materiais e recursos adaptados.

Andrade, Pacheco e Farias (2006) também enfatizam o papel da formação como elemento fundamental para a permanência de alunos com deficiência na graduação. Afirmam que a inclusão no ensino superior demanda adaptar o acesso ao conteúdo desenvolvido nas disciplinas e preparar os professores e funcionários para o atendimento às necessidades educacionais específicas desse aluno em sala de aula e também nos demais setores e serviços da instituição.

Ao discorrer sobre como percebem sua atitude frente ao aluno com deficiência, os docentes apresentaram 41 respostas. A maior incidência de respostas demonstra uma percepção positiva, com atitude pró-ativa e responsável do professores em relação ao aluno com deficiência que procuram, na medida do possível, garantir o acesso aos conteúdos. O diálogo inicial foi a atitude mais usada. Por meio de conversas, os professores tentaram avaliar a situação e conhecer as necessidades do aluno. Alguns docentes relataram que tais atitudes nem sempre são suficientes, gerando um sentimento de frustração por não alcançarem os objetivos 
previstos. Uma professora afirmou: "Penso que poderia ter sido muito melhor. Não me senti suficientemente preparada para isso, em especial no caso da aluna com deficiência visual. Não acredito que eu tenha conseguido favorecer como deveria sua inclusão".

Outro aspecto importante constatado é a abertura dada por alguns professores colocando-se à disposição do aluno para colaborar: "Minha atitude foi sempre de respeito e preocupação. Procurei apoio para melhor atendê-los e, também, conversava com eles para ver o que necessitavam, o que sugeriam para o trabalho pedagógico." O envolvimento do professor também foi observado no estudo de Moreira e cols. (2011) quando, em entrevista com alunos com deficiência no ensino superior, verificaram que os professores não estavam alheios à inclusão e demonstravam preocupação com esse alunado.

Além do diálogo, o uso da experiência docente foi outra atitude muito utilizada pelo professor. Estudos de Baptaglin e Souza (2012) corroboram essa prática e indicam que a maioria dos docentes, quando se depara com a realidade de um estudante incluído em sua classe, tem se alicerçado nos conhecimentos advindos das experiências anteriores.

Todavia, é nítida a consciência que os docentes têm a respeito da atitude que tomam na sala de aula frente ao aluno com deficiência, já que percebem que a fragilidade de suas ações pode prejudicar o aluno, conforme se constata nessas respostas: "O mais surpreendente foi descobrir que tinha um aluno com baixa visão no curso apenas quando ele foi meu aluno, no segundo ano, e, ainda assim, apenas no final da disciplina, quando da realização de uma prova. 0 aluno aproximava muito a folha dos olhos e eu o indaguei a respeito."; "Acredito que minha atitude foi positiva e procurei incluir o aluno à turma, segundo meus parcos conhecimentos do assunto. Contudo, a falta de preparo técnico-teórico e de auxílio profissional inviabilizaram o aproveitamento do aluno."

Os professores percebem, ainda, a sua própria resistência para aprender a lidar com a situação e a precariedade da faculdade. "A FFC carece de pessoal qualificado, em tempo integral, rodando entre os conselhos de curso, atendendo fora de sala de aula alunos e famílias, oferecendo cursos aos docentes - que são muito resistentes - apesar de serem sensíveis ao tema."

Outra atitude, em menor número, referiu-se ao tratamento igualitário para todos os alunos, independentemente de ele ter ou não deficiência, conforme segue: " $A$ atitude que tenho com o aluno com deficiência é semelhante a que tenho com os demais alunos, ou seja, atitude de acolhimento, respeito, incentivo, etc.". Vale lembrar que a igualdade é um princípio fundamental da educação inclusiva e deve atrelar-se à equidade, ou seja, é preciso garantir as mesmas oportunidades de aprendizagem, considerando os ajustes necessários a cada situação específica, a fim de se alcançar uma educação de qualidade. Afinal,

Inclusão de um estudante com necessidades especiais na Universidade não implica um "nivelar por baixo". Não significa mesmo que os docentes tenham que reduzir o seu nível de exigência, infantilizem os seus alunos e abdiquem de valores que consideram essenciais. É sim uma oportunidade para refletir sobre a inevitabilidade, a correção, as vias de acesso, as metodologias e a filosofia curricular e de preparação profissional das suas práticas. (Rodrigues, 2004, p. 4).

\section{Conclusão}

No Brasil, o discurso da educação para todos, que se baseia no ideal de igualdade e de convivência com a diversidade, está se fortalecendo a cada dia por meio das políticas públicas vigentes, alcançando paulatinamente $\mathrm{o}$ nível superior de ensino. Desvendar como os docentes da FFC - Unesp/Marília estão percebendo e enfrentando essa realidade foi o foco da pesquisa. Como se baseou em um estudo de caso, poderia trazer uma possibilidade de generalização limitada, entretanto, os resultados obtidos, quando comparados a outros importantes estudos, demonstraram similaridades e, além disso, sugerem reflexões importantes, tais como o posicionamento favorável dos professores em relação à inclusão, problemas na formação do professor do ensino superior para atuar com o aluno com deficiência na sala de aula e a falta, na instituição, de uma política inclusiva efetiva capaz de prover condições de acesso e de permanência na universidade do aluno com deficiência.

Faz-se nítido que os docentes ainda se sentem inseguros e despreparados para ensinar tal alunado, fenômeno esse que pode ser explicado pelo tipo de formação que tiveram que, de forma geral, é excelente quando analisada no âmbito da formação na graduação e pós-graduação, porém, pelo que foi verificado na pesquisa, é insatisfatória quando relacionada às questões da educação inclusiva. Além disso, quando tratado durante a formação, tal conhecimento foca aspectos teóricos, filosóficos e legais em detrimento a aspectos práticos importantes como o uso de recursos e metodologias de ensino diferenciadas, adequações curriculares ou formas alternativas de avaliação de aprendizagem de alunos com necessidades educacionais específicas.

Outro aspecto evidenciado por esse grupo de professores é que eles precisam do apoio e do suporte da instituição, e que a conjuntura atual da universidade em questão é deficitária e impõe aos alunos que conseguem alcançar a universidade barreiras arquitetônicas, atitudinais, comunicacionais e curriculares. Tal situação não parece muito diferente de outras instituições universitárias, refletindo o despreparo e desconhecimento dos professores e gestores deste nível de ensino.

Comparativamente ao que vem ocorrendo nas universidades federais de ensino superior espalhadas pelo país, em que se verifica a expansão, ainda que gradual, da política educacional inclusiva por meio do incentivo à lei de cotas que respalda não só o acesso, mas também a permanência, além do financiamento de projetos para instalação de núcleos de acessibilidade, a FFC-Unesp/Marília, conforme demonstrado pelos docentes, encontra-se em desvantagem. Mesmo manifestando boas intenções e conhecendo 
os princípios inclusivos que deveriam permear a sua prática pedagógica, os professores relataram que não têm o aparato institucional para efetivar as mudanças necessárias e nem suporte de uma equipe de orientação para discussões sobre as dificuldades inerentes à operacionalização desse processo. Exemplo disso é que nessa faculdade não há intérpretes para alunos com surdez, bem como serviço de apoio especializado para o aluno com deficiência e seu professor.

O curso superior no Brasil, em especial a universidade pública, de acordo com a legislação vigente, fundamenta-se na perspectiva educacional inclusiva. Por essa razão, todas as unidades e cursos, tanto no âmbito federal como no estadual, deveriam garantir condições de acessibilidade em seus processos seletivos e depois de permanência, de forma que o aluno com deficiência pudesse alcançar o sucesso acadêmico e a formação profissional.

Ao contrário disso, tradicionalmente, a instituição de ensino superior mantém a função de selecionar e apoiar os melhores e valorizar o desempenho individual dos alunos. Constitui uma instância de educação que possui poder, impregnada de conservadorismo, em que o professor é o detentor de conhecimento e o aluno é o receptor, devendo se responsabilizar sozinho pelo sucesso ou fracasso de sua aprendizagem. Para o docente expert em determinada área de estudo, mas que não tem conhecimento sobre educação inclusiva, ensinar um aluno com deficiência constitui um imenso desafio. Isso porque todo seu amplo e profundo conhecimento pode não ser suficiente. Precisa estar aberto para se conectar a outros saberes que tratam de estratégias, recursos, metodologias e práticas pedagógicas diferenciadas, bem como trabalhar de forma colaborativa e articulada com outros profissionais.

Enfim, ao revelar a percepção de docentes de um contexto específico, o estudo permitiu inferir que a inclusão no ensino superior é uma realidade que vem se constituindo lentamente, ainda de forma precária, reproduzindo, talvez, a lógica de como esse mesmo processo ocorreu e ocorre na educação básica. Constitui um problema a ser urgentemente enfrentado pela comunidade universitária, em especial pelos gestores, que precisam implantar uma política inclusiva, e pelos docentes diretamente envolvidos na produção de conhecimento e na prática docente junto ao aluno com deficiência. Nesse contexto, seria interessante criar nos ambientes acadêmicos grupos para discussão sobre o tema, com o envolvimento de toda a comunidade universitária, professores, alunos, funcionários e gestores. Afinal, é por meio do acesso ao conhecimento, por meio da troca de ideias e principalmente da articulação e mobilização social que as instituições, sentindo-se pressionadas, poderiam fomentar projetos e implementar ações a fim de tornar o curso superior um espaço cada vez mais democrático e inclusivo em nosso país.

\section{Referências}

Andrade, M.S.A.; Pacheco, M.L.; Farias, S.S.P. (2006) Pessoas com deficiência rumo ao processo de inclusão na educação superior. Conquer, 1, 1-5, Recuperado: 28 abr. 2016. Disponível: http://issuu.com/uc-para-odos/docs/13

André, M.E.D.A. (2005). Estudo de caso em pesquisa e avaliação educacional._Brasília: Liberlivro.

Baptaglin, L.A.; Souza K.M. (2012) Inclusão na educação superior: uma revisão das produções atuais. Anais do XVI Simpósio de ensino, pesquisa e extensão, 3. Santa Maria, RS, Brasil: Unifra. Recuperado: 04 jul. 2016. Disponível: http://www.unifra.br/eventos/ sepe2012/ Trabalhos/5325.pdf.

Brasil. Ministério da Educação (1996) Aviso Circular n 277. Brasília: MEC. Recuperado: 14 abr. 2016. Disponível: http://portal.mec.gov. br/seesp/arquivos/pdf/aviso277.pdf.

Brasil. Ministério da Educação (2008). Política de Educação Especial na Perspectiva da Educação Inclusiva. Brasília: MEC. Recuperado: 14 abr. 2016. Disponível: http://portal.mec.gov. br/arquivos/pdf/ politicaeducespecial.pdf.

Castanho, D.M.; Freitas, S.N. (2006) Inclusão e prática docente no ensino superior. Revista Educação Especial, (27), 85-92. Recuperado: 28 abr. 2016. Disponível: http://cascavel.ufsm.br/revistas/ojs2.2.2/ index.php/educacaoespecial/article/view/4350/2557.

Castro, S.F.; Almeida, M.A. (2014) Ingresso e Permanência de Alunos com Deficiência em Universidades Públicas Brasileiras. Revista Brasileira de Educação Especial 2(20), 179-194. Recuperado: 3 out. 2016. Disponível: http://www.scielo.br/scielo.php?pid=S14136 5382014000200003\&script=sci_abstract\&tlng=pt.

Decreto $n^{\circ} 3.298$ de 20 de dezembro de 1999 (1999, 20 de dezembro). Regulamenta a Lei $n^{\circ} 7.853 / 1989$. Brasília: Presidência da República. Recuperado: 14 abr. 2016. Disponível: http://www. planalto.gov.br/ccivil_03/decreto/d3298. htm.

Decreto $n^{\circ} 5.296$ de 2 de dezembro de 2004 (2004, 2 de dezembro). Regulamenta as Leis n. 10.048/2000, que dá prioridade de atendimento às pessoas que especifica, e n. 10.098/2000, que estabelece normas gerais e critérios básicos para a promoção da acessibilidade das pessoas portadoras de deficiência ou com mobilidade reduzida, e dá outras providências. Recuperado: 14 abr. 2016. Disponível: http://www.planalto.gov.br/ccivil_03/_ Ato2004-2006/2004/Decreto/D5296.htm.

Decreto $n^{\circ} 5.626$ de 22 de dezembro de 2005 (2005, 22 de dezembro). Regulamenta a Lei $n^{\circ} 10.436 / 2002$, que dispõe sobre a Língua Brasileira de Sinais - Libras. Recuperado: 13 mai. 2016. Disponível: http://www. planalto.gov.br/ccivil_03/_ato20042006/2005/decreto/d5626.htm.

Ferrari, M.A.L.D.; Sekkel M.C. (2007) Educação Inclusiva no Ensino Superior: Um Novo Desafio. Revista Psicologia: Ciência e Profissão, 4(27), 636-647. Recuperado: 04 out. 2016. Disponível: http://www.scielo.br/scielo.php?script=sci_arttext\&pid $=$ S1414-98932007000400006. 
Guerreiro, E.M.R.; Almeida, M.A.; Silva Filho, J.H. (2014). Avaliação da satisfação do aluno com deficiência no ensino superior. Avaliação, 1(19), 31-60. Recuperado: 04 out. 2016. Disponível: http://www.scielo.br/scielo.php?script=sci_arttext\&pid $=$ S1414-40772014000100003.

Instituto Nacional de Estudos e Pesquisas Educacionais Anísio Teixeira [Inep] (2015). Censo da Educação Superior 2015: resumo técnico. Brasília: Inep. Recuperado: 12 fev. 2017. Disponível: http://download.inep.gov.br/download/superior/censo/2015/ resumo_tecnico_censo_educacao_superior_2015.pdf.

Lei n. 9.394, de 20 de dezembro de 1996 (1996, 20 de dezembro). Estabelece as diretrizes e bases da educação nacional. Brasília, DF: Diário Oficial [da] República Federativa do Brasil., p.27.833.

Lei $n^{\circ}$ 13.146/2015 de 6 de julho de 2015 (2015). Institui a Lei Brasileira de Inclusão da Pessoa com Deficiência (Estatuto da Pessoa com Deficiência). Recuperado: 23 mar. 2016. Disponível: http://www. planalto.gov.br/ccivil_03/_Ato2015-2018/2015/Lei/L13146.htm.

Melo, F.R.L.S.; Gonçalves, M.J. (2013) Acesso e permanência de estudantes com deficiência física no ensino superior. In: Melo, F.R.L.S. (Org.), Inclusão no ensino superior: docência e necessidades educacionais especiais (pp. 83-104). Natal: EDUFRN.

Moreira, L.C.; Bolsanello, M.A.; Seger, R.G. (2011) Ingresso e permanência na Universidade: alunos com deficiências em foco. Educar em Revista, (41), 125-143. Recuperado: 21 set. 2016. Disponível: http://www.scielo.br/scielo.php?script=sci_artte xt\&pid=S0104-40602011000300009.

Pacheco, R.V.; Costa, F.A.T. (2006) O processo de inclusão de acadêmicos com necessidades educacionais especiais na Universidade Federal de Santa Maria. Revista Educação Especial, (27), 151-170. Recuperado: 28 abr. 2016. Disponível: http:// cascavel.ufsm.br/revistas/ojs-2.2.2/index.php/educacaoespecial/ article/view/4360.

Portaria $n^{\circ} 3.824$ de 07 de novembro de 2003 (2003, 07 de novembro). Dispõe sobre requisitos de acessibilidade de pessoas portadoras de deficiências, para instruir os processos de autorização e de reconhecimento de cursos, e de credenciamento de instituições. Brasília, DF: Diário Oficial [da] República Federativa do Brasil, $n^{\circ}$ 219, Seção 1, p. 1.

Regiani, A.M.; Mól, G.S. (2013) Inclusão de uma aluna cega em um curso de licenciatura em química. Ciência \& Educação, 19(1), 123134. Recuperado: 03 set. 2016. Disponível: http://www.scielo.br/ scielo.php?script=sci_arttext\&pid=S1516-73132013000100009.

Rodrigues, D. (2004)Ainclusão na universidade: limites e possibilidades da construção de uma universidade inclusiva. Revista Educação Especial, (23), 9-15. Recuperado: 28 abr. 2016. Disponível: http:// cascavel.ufsm.br/revistas/ojs-2.2.2/index.php/educacaoespecial/ article/view/4951.

Souza, L.M. (2008). A inclusão de alunos com deficiência na Universidade Federal do Piauí: concepções de professores. Dissertação de Mestrado em Educação, Universidade Federal do Piauí, Teresina, PI.

Apoio Financeiro: Pesquisa Acessibilidade no Ensino Superior Obeduc/Capes

Proc. 23038.002628/2013-41

License information: This is an open-access article distributed under the terms of the Creative Commons Attribution License (type CCBY), which permits unrestricted use,distribution and reproduction in any medium, provided the original article is properly cited.

Recebido em: 14 de dezembro de 2017 Aprovado em: 23 de janeiro de 2018

\section{Sobre as autoras}

Rosimar Bortolini Poker (poker@marilia.unesp.br) Universidade Estadual Paulista (Unesp) - Faculdade de Filosofia e Ciências - Campus de Marília, SP. Doutora em Educação. https://orcid. org/0000-0001-8019-6506

Fernanda Oscar Dourado Valentim (ferdourado2008@hotmail.com) Universidade Estadual Paulista (Unesp) - Faculdade de Filosofia e Ciências - Campus de Marília, SP. Doutoranda em Educação. https://orcid.org/0000-0002-7920-0456

Isadora Almeida Garla (isadora.garla@gmail.com) Universidade Estadual Paulista (Unesp) - Faculdade de Filosofia e Ciências - Campus de Marília, SP. Graduação em Pedagogia. https://orcid.org/0000-0002-0192-5318 